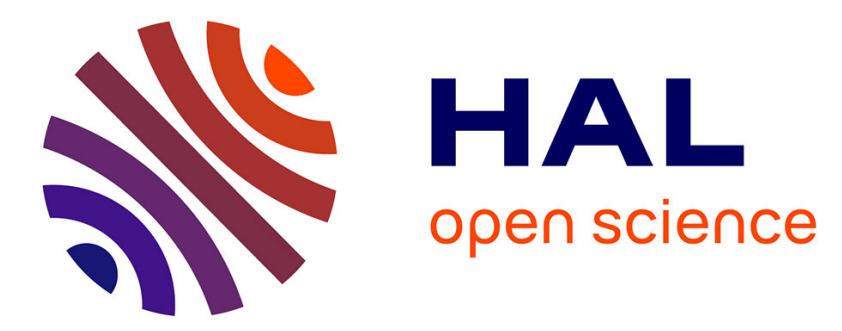

\title{
Intraluminal flexible sheath for the protection of low anastomosis after anterior resection: results from a First-In-Human trial on 15 patients
}

\author{
Antonio D’urso, Niels Komen, Jérémie H. Lefevre
}

\section{To cite this version:}

Antonio D'urso, Niels Komen, Jérémie H. Lefevre. Intraluminal flexible sheath for the protection of low anastomosis after anterior resection: results from a First-In-Human trial on 15 patients. Surgical Endoscopy, 2019, 10.1007/s00464-019-07279-8 . hal-02414262

HAL Id: hal-02414262

https: / hal.sorbonne-universite.fr/hal-02414262

Submitted on 16 Dec 2019

HAL is a multi-disciplinary open access archive for the deposit and dissemination of scientific research documents, whether they are published or not. The documents may come from teaching and research institutions in France or abroad, or from public or private research centers.
L'archive ouverte pluridisciplinaire HAL, est destinée au dépôt et à la diffusion de documents scientifiques de niveau recherche, publiés ou non, émanant des établissements d'enseignement et de recherche français ou étrangers, des laboratoires publics ou privés. 
1 Intraluminal flexible sheath for the protection of low anastomosis after anterior resection:

\section{Results from a First-In-Human trial on 15 patients}

3 Antonio D’Urso, $(\mathrm{MD}, \mathrm{PhD})^{1}$, Niels Komen $(\mathrm{MD}, \mathrm{PhD})^{2}{ }^{2}$, Jérémie H. Lefevre $(\mathrm{MD}, \mathrm{PhD})^{3}$ 4

5 1. University Hospital of Strasbourg, Department of General, Digestive, and Endocrine 6 Surgery, Strasbourg, France 7

8 2. Department of Abdominal Surgery, University Hospital Antwerp, University of Antwerp, 9 Edegem, Belgium

3. Sorbonne Université, Department of Digestive Surgery, AP-HP, Hôpital Saint Antoine, F1275012 , Paris, France. 


\section{1}

ABSTRACT

\section{Background}

\section{Methods} 14 prospectively.

\section{Results}

\section{Conclusion} results.

3 Defunctioning ostomy is commonly used to protect patients from anastomotic leakage

4 complications after low anterior resection but is fraught with its own deleterious effects. This

5 first-in-human study examines the safety and preliminary efficacy of Colovac, an anastomosis

6 protection device. The Colovac consists of a flexible bypass sheath, placed in the lumen of the

7 colon and anchored above the anastomosis using a vacuum-stent.

1015 patients underwent anterior resection (AR) with anastomosis protection by a Colovac, at 3 11 European-centers. After 14 days, the anastomosis integrity was examined by CT-scan and 12 endoscopy. The device was then endoscopically removed. Data regarding demographics, 13 surgical details, 30 day post-operative complications, and patient satisfaction were collected

15 patients (10 male) underwent laparoscopic AR with Colovac placement. Preoperative neoadjuvant therapy was administered to $54 \%$ of patients. Device placement was uneventful in all patients with a median duration of $7 \mathrm{~min}$ and placement was judged as easy or very easy in 93\% of the cases. Patients did not report major discomfort during the 14 days. Endoscopic removal (10 min) was judged as easy or very easy in $87 \%$ of the cases. Absence of feces below the Colovac anchoring site was observed in $100 \%$ of the cases. 4 anastomotic leakages were observed (including 3 device migrations). Overall 5 patients (33\%) required a planned stoma creation. At 3 months, 1 had already been closed.

Colovac provides a minimally-invasive protection of the anastomosis during the healing process by avoiding the need for a diverting ostomy for two thirds of patients who will not experience anastomotic complications and allowing safe conversion to standard of care for patients requiring extended anastomotic protection. A larger study is ongoing to confirm these

Keywords: rectal cancer; stoma; bypass sheath; stent; anastomotic leakage. 


\section{1}

INTRODUCTION

2 Colorectal cancer represents the third most common cancer and the second most common cause

3 for cancer mortality worldwide, with 1.8 million diagnoses and 881,000 expected deaths in

4 2018. [1] Despite improvement in the peri-operative management of anterior resection for rectal

5 cancer, the rate of anastomotic leakages is still around $17 \%$ in recent randomized studies. [2, 3]

6 Anastomotic leakage is associated with increased morbidity and mortality, rate of definitive 7 stoma [4, 5] and recurrence [6]. The only protective measure is the use of a diverting stoma. [7] 8 Although the anastomosis typically heals in 10-15 days, the ostomy remains for 2-6 months. 9 This timeframe is necessary for ostomy maturation (2 months) or the accomplishment of 10 adjuvant therapy (3-6 months). During this period, patients are exposed to complications (up to $1177 \%$ ) such as dehydration, peristomal skin breakdown, skin burn, stoma prolapses or retraction 12 in addition to the psychological impact of carrying a stoma.

13 Additionally, stoma closure carries a risk of postoperative complications around $8 \%$, including 14 anastomotic leakage of the ileo-ileal anastomosis (1\%). [8] Following stoma closure, the Moreover, around $20 \%$ of ostomies are not reversed. [10] This has a significant impact on the quality of life of the patients, and implies life-long maintenance and associated costs.

Therefore, there is a critical need to develop a device which would protect the anastomosis temporarily to reduce complications associated with ostomies and takedown interventions, and would maintain digestive tract functionality for better recovery outcomes. Attempts to develop medical devices based on a flexible lining to protect the anastomosis proved the applicability of the concept [11], but anchoring these devices by an easily reversible mechanism proved challenging. $[12,13]$

The Colovac Colorectal Anastomosis Protection Device (Colovac, SafeHeal, France) is a single use, temporary intraluminal bypass device consisting of a flexible bypass sheath, which is endoscopically placed into the lumen of the colon and anchored above the anastomosis using a vacuum stent. The Colovac thus creates a functional colorectal anastomosis protection reducing contact of fecal content with the anastomotic site. Until now, no clinical data were available to evaluate this device.

The aim of this first-in-human pilot study was to evaluate the preliminary safety and efficacy of the Colovac. 


\section{MATERIALS AND METHODS}

$3 \quad$ Study Design

4 This clinical study was a pilot, prospective, open-label, multi-center (Europe), single arm study, 5 which enrolled 15 subjects undergoing low anterior resection with total mesorectal excision 6 (TME) for rectal cancer. Procedures were performed by experienced colorectal surgeons at 7 three European tertiary centers (Hospital Saint-Antoine, Paris; IHU, Strasbourg; UZA, 8 Antwerp). The study protocol, its amendments, and study associated documents were reviewed 9 and approved by the appropriate Ethics Committee (EC) and Competent Authorities (CA). This study was registered online on the ClinicalTrials.gov website under the following identifier: 11 NCT03352570.

12 It was conducted in accordance with the standard ISO 14155:2011 and the recommendations 13 guiding physicians in biomedical research involving human subjects adopted by the $18^{\text {th }}$ World 14 Medical Assembly, Helsinki, Finland, 1964 and later revisions.

15

\section{Objective \& endpoints}

The primary study objective was to demonstrate safety using the device. It was assessed by recording all Serious Adverse Events (SAEs) in terms of type, frequency, severity and relationship with the use of the Colovac during 3 months follow-up. Any readmission, unscheduled admission greater than 24 hours or initial hospitalization extending beyond a 14day average length of stay due to an adverse event were considered as a serious adverse event.

The secondary objectives were to assess the clinical efficacy of bypass anastomosis protection, the overall procedural feasibility, the procedural success with placing and retrieving the device, the average procedure time, and the patient acceptance of the device.

\section{Patients}

Patients who underwent an anterior resection (AR) with TME with low anastomosis less than $20 \mathrm{~cm}$ from the anal verge were considered for inclusion. 
1 Inclusion criteria were as follow: age $\geq 18$ and $\leq 65$ years old with an indication for colorectal 2 resection, eligible to bear a loop ileostomy, willing to comply with protocol-specified follow3 up evaluations and having signed a written informed consent.

4 Exclusion criteria were the following: patient with inflammatory bowel disease, pregnant or 5 nursing female subject (a pregnancy test should be conducted the day prior to the procedure for 6 all women of childbearing age), known allergy to nickel or other components of the Colovac, 7 any significant medical condition which, in the investigator's opinion, may interfere with the subject's optimal participation in the study, subject already enrolled in another investigational

9 drug or device study that has not completed the primary endpoint or that clinically interferes 10 with the endpoints of this study, or patient unable to give consent.

11 After inclusion, subjects were studied pre and post procedure, with scheduled follow- up at 1, 122,4 weeks and 3 months, as well as a phone call at 6 weeks.

\section{Data collection}

Safety and efficacy of the Colovac were analyzed during the implantation period (0-14 days) and after 90 days follow-up. Data regarding demographics, surgical details, 90-day morbidity and patient satisfaction were collected prospectively. All stapled anastomoses were considered as colorectal anastomoses and all handsewn anastomoses were considered as coloanal anastomoses.

Feasibility was defined by the ability to introduce, deploy and retrieve the Colovac to/from the desired location in the colon. Procedural success was defined by acute efficacy placing the device at the desired location. Procedure time was defined as time from insertion of the introducer to the vacuum system being ready to be connected and begin vacuum application. Migration rate was defined by the number of devices migrated over the anastomosis divided by the number of devices placed. The sheath internalization is defined as the retraction of the Colovac sheath within the colon lumen, and no more external protrusion through the anus. Patient acceptance and tolerability was analyzed using the NIH's PROMIS health measurement questionnaires to assess parameters like pain, bowel incontinence, constipation, diarrhea, or anxiety and social isolation. [14]

An independent Data Safety Monitoring Board (DSMB) has been appointed by the sponsor to assess, at monthly intervals, the progress of the clinical investigation, the safety data and the 
1 critical performance endpoints, and to recommend to the sponsor whether to continue, suspend, 2 modify, or stop the clinical investigation. All members of the DSMB had no relationship with 3 the sponsor or the investigators.

\section{$4 \quad$ Investigational device}

5 The Colovac is intended to reduce contact of faecal content with the colorectal anastomotic site, 6 following colorectal surgery (open or laparoscopic). It is indicated to be used in adult patients 7 scheduled to receive a diverting loop ileostomy following colorectal surgery, who have been 8 assessed by a multi-disciplinary team as per standard of care. The Colovac is a short-term 9 minimally-invasive device delivered and positioned through the anus. It is a sterile, single use disposable device consisting of one introducer pre-loaded with the Colovac.

The Colovac is made of two elements: an anchor made of a covered stent delimiting a vacuum chamber connected to a vacuum tube; a flexible polymer cylindrical sheath attached to the anchor, covering the anastomosis with appropriate length so that it protrudes about five centimeters outside the patient's anus (Figure 1) in order to avoid any feces backflow in the colon at the open extremity of the sheath and to allow surveillance of the stent placement.

\section{Procedure}

Patients received fibre-free dietary regimen 2-3 days before surgery and mechanical bowel preparation (PEG based) the day before surgery (3-4 L). After the creation of the anastomosis, Colovac was inserted endoluminally through the anus under direct laparoscopic or laparotomic vision, using a dedicated flexible introducer (external diameter $17 \mathrm{~mm}$ ) preloaded with Colovac. Once positioned at the correct location, approximatively $20 \mathrm{~cm}$ above the anastomosis, the stent was delivered and expanded. Upon removal of the introducer, the sheath and the vacuum tube were self-deployed distally past the anastomosis and the anus. After a vacuum efficacy test, the vacuum tube was then connected to a vacuum system (Redon vial of $600 \mathrm{ml}$ ), fixating the mucosa against the stent during the implantation period. Redon vacuum sets are meant for postoperative wound drainage. It consists of a high vacuum drainage system. The set is connected to the Colovac device via the aspiration tube, using a specific connector. The device was left in situ up to fourteen days post-implantation. Use of a pelvic drain was left at the discretion of the investigator. 
1 The surgeon was asked to grade the ease of introducer introduction and removal using a 5 points

2 Lickert scale ranked from very easy to impossible.

3 A low fiber diet was given while the stent was in place. For the purpose of the study, all patients

4 remained hospitalized for the entire duration of the Colovac implantation. Follow-up included

5 daily clinical examination of the abdomen and the sheath length, CRP levels at post-operative

6 day 1,3 and 5. [15, 16] After 12 to 13 days, the anastomosis integrity was examined by a CT

7 scan with IV contrast agent and/or trans anal injected contrast CT-scan before taking the patient

8 to the OR for the retrieval. The Colovac was retrieved at day 14 in the OR. An endoscopy was

9 performed between the sheath and the colonic mucosa to verify the anchoring site and the

10 absence of stool between the sheath and the colonic wall. Then the device was removed 11 endoscopically through the anus by pulling on the retrieval loops located at the distal and 12 proximal ends of the stent.

\section{RESULTS}

\section{Subjects demographics and surgical procedures}

16 Fifteen patients were enrolled between November 2017 and June 2018 at three sites in Europe 17 (Hôpital Saint Antoine, Paris, France n=8 - CHU Strasbourg, n=3 - UZA, Antwerp, Belgium, $18 \mathrm{n}=4$ ). One patient was screened but not included in this study as he declined participation in a 19 clinical trial. Patient characteristics and surgical procedures details are summarized in Table 1. 20 There were 10 men (67\%) with a median age of 60 (46-70) years. All patients were diagnosed 21 with a rectal cancer. Majority of patients were staged cT3 (53\%). 67\% of patients received 22 neoadjuvant radiotherapy and/or chemotherapy.

23 All anterior resections were performed through a laparoscopic approach, $26.7 \%$ of patients 24 underwent a coloanal anastomosis and $60 \%$ of cases received a side-to-end anastomosis.

25 Two patients (14\%) had associated procedures (right hepatectomy and two wedge resections 26 for synchronous metastatic lesions). Details of surgical procedures are given in Table 1.

\section{Colovac procedure}

28 - Colovac placement and anchoring 
1 The Colovac placement was scored as very easy or easy by the surgeon in $93 \%$ of cases. The 2 median duration of placement was 7 (3-10) min. In 1 out of the 15 cases (7\%), the Colovac was 3 accidently pulled down during introducer removal. The device was then removed and replaced 4 by a second one, without additional difficulties. Details about Colovac placement are 5 summarized in Table 2.

6 One (7\%) patient experienced a Colovac sheath internalization (retraction from anus) at Day 1. 7 As the patient was asymptomatic, he was closely monitored but nothing was done to reverse 8 the sheath internalization. The device was removed according to the protocol on Day 14.

9 Of the 15 devices implanted, 3 (20\%) migrated before the end of the implantation period (2 device malfunctions related to a vacuum defect and 1 device misplacement (stent component of the Colovac device placed in immediate proximity (i.e. $4 \mathrm{~cm}$ ) of the distal end of the Jpouch)). These three patients experienced moderate fever at post-operative D3 to D5 and a control CT-scan was performed showing device migration. Devices were endoscopically removed in the operating room and conversion to loop ileostomies were performed without any complication in order to extend the anastomosis protection. For 2 patients, conversion to loop ileostomy was performed during the course of the implantation period, while for the third patient, loop ileostomy conversion was considered at the time of scheduled removal, owing to the presence of a millimetric fistula communicating with the vaginal wall, resulting from a vaginal wall laceration during the initial surgery.

\section{- Colovac retrieval}

All devices were removed endoscopically (14/15) or manually (1/15), without the need for surgery at postoperative Day 4 to 17 days. All Colovac retrievals were scored as very easy or easy by the endoscopist except the two (13\%) first cases of the study, judged as difficult given the time required for removal (15 minutes). The median duration of the retrieval procedure was 10 (5-20) minutes. Following successful Colovac retrieval at postoperative day 14, all patients without anastomotic leakage $(n=10)$ were discharged the day after the endoscopic retrieval procedure.

The absence of feces below the Colovac anchoring site was confirmed by endoscopy performed between the colonic wall and the sheath in all the patients with the Colovac in place. The mucosal appearance was endoscopically evaluated and rated as normal or inflammatory in $80 \%$ of cases above the anchoring site and at the anastomotic level. The remaining $20 \%$ didn't require any further surveillance even if rated as ulcered or bleeding. At the device anchoring 
1 site, in $27 \%$ of patients, small bleeding lesions were experienced, not requiring any surveillance.

2 Details about Colovac retrieval procedures are summarized in Table 2.

3 Post-operative course (Figure 2)

4

\section{- Post operative morbidity}

The overall postoperative morbidity was 47\% ( $\mathrm{n}=9$ ). (Table 3). Major morbidity (Dindo III-IV) was $33 \%$.

Major postoperative complications during the Colovac implantation period were device migrations with anastomotic leakages (20\%), and incomplete anastomosis healing diagnosed at the end of the Colovac implantation (13\%). They were all managed by an ostomy placement for longer protection of the anastomosis. One (7\%) patient with a colonic J pouch anastomosis who experienced a Colovac migration in the first week after the implantation was operated for the removal of the device, colonic lavage and a loop ileostomy creation. Unfortunately he presented few hours later a peritonitis requiring a second re-intervention for abdominal lavage. The recovery after the second operation was uneventful.

The other two patients who presented with Colovac migration during the implantation period were re-operated. The Colovac was removed and the loop ileosotmy created without any complications. No other patients experienced during the implantation period any morbidity related to the anastomosis. As reported in the table 3 one patient with previous right hepatectomy developed an ascites medically treated. Post-operative complications during the post-Colovac retrieval period (14 days to 3 months) were dominated by pelvic collection ( $\mathrm{n}=3$ ) in patients who did not experience leaks during the immediate post-operative period. All pelvic collections were managed conservatively by antibiotics.

- Patient acceptance and success rate

Colovac was well tolerated by patients with a full or very good acceptance of vacuum system presence for $80 \%$ of them and a NIH's PROMIS median score of 15 (8-20) at 3 months (Table 3). The Colovac device provided effective protection of the anastomosis in 12/15 (80\%) subjects during the 14 day implantation period and allowed avoidance of ostomy creation in 10/15 (67\%). Among the 5 patients converted to ostomy, 1 (7\%) had his stoma reversed at 3 months, 2 were still under chemotherapy treatment and the remaining two are planned to have a stoma closure at 6 months following surgery. 


\section{DISCUSSION}

3 The current standard of care to minimize the sequelae of anastomotic leakage is the creation of 4 a temporary diverting ostomy in order to protect the anastomosis [7]. A recent meta-analysis 5 by Phan et al. of 8 randomized studies with 892 anterior resections confirms that a stool diversion following rectal surgery can effectively reduce anastomotic complications. [17] The

7 Colovac presents an alternative to ostomy by creating a functional intraluminal bypass which

8 is endoscopically placed into the lumen of the colon and anchored above the anastomosis using 9 a vacuum stent.

This first preliminary study showed that the Colovac procedure is feasible with promising initial results in terms of protection of the anastomosis: $80 \%$ of subjects protected during the 14 days implantation period and avoidance of ostomy creation in 10/15 (67\%). Given the known incidence of clinical complications due to ostomy creation and ostomy reversal, avoidance of ostomy could potentially reduce morbidity in these patients. Typically, ostomy patients are exposed to a $43 \%$ postoperative complication rate (including risk of readmission, dehydration, and acute renal failure). [8] Most patients with a temporary ileostomy will keep their ostomy at least 3 months, and it is not unusual that the ostomy is left in place much longer, and for $20 \%$ of patients it becomes permanent. [8] Closure of the temporary ileostomy is associated with a low mortality, but the morbidity may be more than $20 \%$. [8]

Of the 15 Colovac devices placed, 3 migrated before the end of the implantation period (2 device malfunctions related to a vacuum defect, 1 device misplacement related to the placement of the stent component of the device in the immediate proximity of the distal end of the Jpouch). For those 3 cases, initial device placement and introducer removal were uneventful.

The endoscopic use of stents in the gastrointestinal tract has been instrumental in the treatment of unresectable esophageal cancer, esophageal leak, and as a bridge to surgery in case of colonic obstruction. The historical use of colorectal stents for the protection of anastomotic leak has been limited due to technical issues, leading to migration of the stent in up to $58 \%$ of patients. [18-20]

Regarding the Colovac migration whose associated conversion to ostomy caused a peritonitis: this case has been considered as probably related to a misplacement of the device and the lavage during the first re-operation. It was the first case of Colovac placement above a colic J-pouch. 
1 The device was placed at $13 \mathrm{~cm}$ above the anastomosis $(3-4 \mathrm{~cm}$ above the distal part of the $\mathrm{J}$ 2 pouch, in front of the sacral promontory). So the distal part of the Colovac was too close to the 3 proximal dilated part of the pouch leading maybe to an ease and early migration of the device.

4 Instructions for use have been revised to recommend device anchoring above the promontory, 5 at $20 \mathrm{~cm}$ above the anastomosis in order to avoid further similar complications. In recent 6 studies, the rate of post-operative peritonitis requiring reintervention ranges between

7 The Colovac-related migration rate (13\%) - related to vacuum defect - reported in the current 8 study is much lower than the migration rate for standard colonic stents reported in the literature 9 and confirms the efficacy of the vacuum system for anchoring the device. Additional 10 surveillance measures have been implemented in order to identify early signs of migration (daily control of the external sheath length) and/or vacuum malfunction, enabling swift action if required (conversion to ostomy for example) and thus reducing the potential complications associated with this migration.

Regardless of the migrations, the incidence of anastomotic leakages in the SAFE-1 study population, during the Colovac implantation period (0-14 days), was 13\%. This rate was within the same range as AL rate reported for similar patient populations receiving a diverting ostomy $(12 \%$ to $17 \%)$. $[2,3,21]$

It is widely accepted that following rectal surgery, some patients will experience anastomotic complications such as anastomotic leakage. The process of anastomotic healing will therefore be longer for these patients.

Regardless of the efficacy of the Colovac at protecting the anastomosis during the first 14 postoperative days, it is anticipated that a proportion of patients will still demonstrate incomplete anastomotic healing as it is the case with systematic stoma diversion. [2, 3] In such cases, the Colovac should be removed and a fecal diversion required to provide long-term anastomotic protection. Results obtained in this first 15-patient cohort are aligned with these observations. It is likely that the rate of conversion to diverting ostomy is inherent to the 27 anastomotic healing problem.

Additionally, a trend toward delayed anastomotic healing and/or fistulisation was observed for patients with evidence of extensive local disease and/or patients for whom colorectal resection was combined with additional surgical procedures such as hepatectomy. The two patients from this cohort who underwent a hepatectomy required stoma conversion. This suggests that a 14 
1 day protection period is likely to be insufficient for this subset of population. Mitigation 2 measures, consisting of improved patient selection criteria have been implemented to reduce 3 the occurrence in the future. The improved patient selection criteria exclude patients for whom rectal surgery is associated with a secondary procedure such as liver resection, due to a higher risk of anastomotic complications requiring prolonged protection and will make the population more homogenous.

In addition to this, we would like to highlight that patients converted to ostomy to ensure a longer protection of their anastomosis have not experienced any major complication related to this conversion surgery except for the peritonitis following the per-operative lavage that required a new intervention. All stoma creations were planned, and not performed in an emergent situation due to the clinical symptoms of the patients.

Clinical complications during the follow-up period were dominated by late pelvic collections (20\%). The occurrence of a collection more than 8 days after the Colovac retrieval is advocating for a late fistulation, as reported in the literature. The nature of the collected liquid converges along those lines. The study from Alves and al. [22] reports a leakage rate between 1 and $4 \%$ after early ostomy closure (between 7 and 14 days), and the study by Yin and al. supports the same rate. [23] Nelson and al. reported intra-abdominal collection rate at $14 \%$ after early ostomy closure (between 14 and 28 days). [24] These late pelvic complications were managed conservatively, by antibiotic treatments.

Regarding procedural feasibility, this study showed that delivery of the Colovac during colorectal surgery and endoscopic device retrieval are feasible and safe. Indeed, no anastomotic trauma was reported by the investigators.

23 In addition, delivery of the Colovac is likely to require less time than ostomy creation with no 24 major differences in terms of hospital stay. The consistent delivery time signifies the simplicity 25 of the procedure, especially when considering that three different physicians placed the devices 26 at differing times.

27 Device retrievals were performed endoscopically or manually. The mean retrieval duration was $2810 \mathrm{~min}$, except for one case, which took longer due to the learning experience. The longer time 29 (15 min) associated with the first case is attributed to the learning curve effect, since colonic 30 stent retrieval is not routinely performed in the standard GI practice. As for the device 
1 placement, the consistent retrieval time after the first cases signifies the simplicity of the 2 procedure.

3 This initial study also provided the first evidence that this novel concept was well-tolerated by

4 patients. Limited discomfort related to the presence of a drain and a sheath through the anus 5 was reported during the 14 day period, which can be counterbalanced by the discomfort 6 associated with the ostomy for a much longer period of time. For the purpose of the study, 7 patients were not discharged before the end of the implantation period (ie. 14 days) but earlier 8 patient discharge could be envisioned in the future.

9 There are some limitations to this study. The number of included patients is low and the study population is a convenience cohort of rectal cancer patients treated at expert centers. Results may not be generalizable to all rectal cancer patients and other centers. Second, the use of Colovac should be limited to patients undergoing rectal resections without concomitant surgery given the associated increased risk of complications.

Other attempts to replace ileostomy by intraluminal approaches confirm the clinical need for minimally invasive protection of colorectal anastomosis. Recently, Reshef, et al reported the use of an intraluminal device (CG-100), confirming the beneficial impact of this approach. [25] However, the patient population addressed in this study was different from our cohort. The mean anastomosis height was $10 \mathrm{~cm}$, demonstrated to be less prone to anastomotic complications than low to very low colorectal anastomosis, as included in our study. [26]

Colovac provides a local, temporary, minimally invasive protection of the anastomosis during the healing process, avoiding the need for a diverting ostomy for patients who will not experience anastomotic complications and allowing safe conversion to standard of care diverting ostomy for patients requiring prolonged anastomotic protection. By optimizing conditions of use and patient selection, Colovac could become an effective patient management alternative for patients undergoing low anterior resection. This should be confirmed in a larger and randomized study.

\section{REFERENCES}


1. Bray F, Ferlay J, Soerjomataram I, Siegel RL, Torre LA, Jemal A (2018) Global cancer statistics 2018: GLOBOCAN estimates of incidence and mortality worldwide for 36 cancers in 185 countries. CA Cancer J Clin 68:394-424

2. Denost $Q$, Rouanet $P$, Faucheron $\mathrm{JL}$, Panis $\mathrm{Y}$, Meunier $\mathrm{B}$, Cotte $\mathrm{E}$, Meurette $\mathrm{G}$, Kirzin $\mathrm{S}$, Sabbagh C, Loriau J, Benoist S, Mariette C, Sielezneff I, Lelong B, Mauvais F, Romain B, Barussaud ML, Germain C, Picat MQ, Rullier E, Laurent C, French Research Group of Rectal Cancer S (2017) To Drain or Not to Drain Infraperitoneal Anastomosis After Rectal Excision for Cancer: The GRECCAR 5 Randomized Trial. Ann Surg 265:474-480

3. Lefevre JH, Mineur L, Kotti S, Rullier E, Rouanet P, de Chaisemartin C, Meunier B, Mehrdad J, Cotte E, Desrame J, Karoui M, Benoist S, Kirzin S, Berger A, Panis Y, Piessen G, Saudemont A, Prudhomme M, Peschaud F, Dubois A, Loriau J, Tuech JJ, Meurette G, Lupinacci R, Goasgen N, Parc Y, Simon T, Tiret E (2016) Effect of Interval (7 or 11 weeks) Between Neoadjuvant Radiochemotherapy and Surgery on Complete Pathologic Response in Rectal Cancer: A Multicenter, Randomized, Controlled Trial (GRECCAR-6). J Clin Oncol 34:3773-3780

4. Celerier B, Denost Q, Van Geluwe B, Pontallier A, Rullier E (2015) The risk of definitive stoma formation at ten years after low and ultra-low anterior resection for rectal cancer. Colorectal Dis

5. Maggiori L, Bretagnol F, Lefevre JH, Ferron M, Vicaut E, Panis Y (2011) Conservative management is associated with a decreased risk of definitive stoma after anastomotic leakage complicating sphincter-saving resection for rectal cancer. Colorectal Dis 13:632-637

6. Mirnezami A, Mirnezami R, Chandrakumaran K, Sasapu K, Sagar P, Finan P (2011) Increased local recurrence and reduced survival from colorectal cancer following anastomotic leak: systematic review and meta-analysis. Ann Surg 253:890-899

7. Matthiessen P, Hallbook O, Rutegard J, Simert G, Sjodahl R (2007) Defunctioning stoma reduces symptomatic anastomotic leakage after low anterior resection of the rectum for cancer: a randomized multicenter trial. Ann Surg 246:207-214

8. Danielsen AK, Park J, Jansen JE, Bock D, Skullman S, Wedin A, Marinez AC, Haglind E, Angenete E, Rosenberg J (2017) Early Closure of a Temporary lleostomy in Patients With Rectal Cancer: A Multicenter Randomized Controlled Trial. Ann Surg 265:284290 

12

9. Maggiori L, Moszkowicz D, Zappa M, Mongin C, Panis Y (2015) Bioprosthetic mesh reinforcement during temporary stoma closure decreases the rate of incisional hernia: A blinded, case-matched study in 94 patients with rectal cancer. Surgery

10. den Dulk M, Smit M, Peeters KC, Kranenbarg EM, Rutten HJ, Wiggers T, Putter H, van de Velde CJ, Dutch Colorectal Cancer G (2007) A multivariate analysis of limiting factors for stoma reversal in patients with rectal cancer entered into the total mesorectal excision (TME) trial: a retrospective study. Lancet Oncol 8:297-303

11. Morks AN, Havenga K, Ploeg RJ (2011) Can intraluminal devices prevent or reduce colorectal anastomotic leakage: a review. World J Gastroenterol 17:4461-4469

12. Egozi L, Sorrento JJ, Golub R, Schultz EH (1993) Complication of the intracolonic bypass. Report of a case. Dis Colon Rectum 36:191-193

13. Bakker IS, Morks AN, Hoedemaker HO, Burgerhof JG, Leuvenink HG, Ploeg RJ, Havenga K (2012) The C-seal trial: colorectal anastomosis protected by a biodegradable drain fixed to the anastomosis by a circular stapler, a multi-center randomized controlled trial. BMC Surg 12:23

14. Hays RD, Bjorner JB, Revicki DA, Spritzer KL, Cella D (2009) Development of physical and mental health summary scores from the patient-reported outcomes measurement information system (PROMIS) global items. Qual Life Res 18:873-880

15. Benoit O, Faron M, Margot N, Creavin B, Debove C, Tiret E, Parc Y, Lefevre JH (2019) C-Reactive Protein Values After Colorectal Resection: Can We Discharge a Patient With a C-Reactive Protein Value $>100$ ? A Retrospective Cohort Study. Dis Colon Rectum 62:88-96

16. Waterland P, Ng J, Jones A, Broadley G, Nicol D, Patel H, Pandey S (2016) Using CRP to predict anastomotic leakage after open and laparoscopic colorectal surgery: is there a difference? Int J Colorectal Dis 31:861-868

17. Phan K, Oh L, Ctercteko G, Pathma-Nathan N, El Khoury T, Azam H, Wright D, Toh JWT (2019) Does a stoma reduce the risk of anastomotic leak and need for reoperation following low anterior resection for rectal cancer: systematic review and meta-analysis of randomized controlled trials. J Gastrointest Oncol 10:179-187

18. Fernandez Lobato R, Pinto I, Maillo C, Paul L, Fradejas JM, Moreno Azcoita M (1999) Rectovesical fistula treated by covered self-expanding prosthesis: report of a case. Dis Colon Rectum 42:812-815 
19. Jeyarajah AR, Shepherd JH, Fairclough PD, Patchett SE (1997) Effective palliation of a colovaginal fistula using a self-expanding metal stent. Gastrointest Endosc 46:367369

20. Paul L, Pinto I, Gomez H, Fernandez-Lobato R, Moyano E (2002) Metallic stents in the treatment of benign diseases of the colon: preliminary experience in 10 cases.

Radiology 223:715-722

21. Matthiessen P, Hallbook O, Andersson M, Rutegard J, Sjodahl R (2004) Risk factors for anastomotic leakage after anterior resection of the rectum. Colorectal Dis 6:462-469

22. Alves A, Panis Y, Lelong B, Dousset B, Benoist S, Vicaut E (2008) Randomized clinical trial of early versus delayed temporary stoma closure after proctectomy. Br J Surg 95:693-698

23. Yin TC, Tsai HL, Yang PF, Su WC, Ma CJ, Huang CW, Huang MY, Huang CM, Wang JY (2017) Early closure of defunctioning stoma increases complications related to stoma closure after concurrent chemoradiotherapy and low anterior resection in patients with rectal cancer. World J Surg Oncol 15:80

24. Nelson T, Pranavi AR, Sureshkumar S, Sreenath GS, Kate V (2018) Early versus conventional stoma closure following bowel surgery: A randomized controlled trial. Saudi J Gastroenterol 24:52-58

25. Reshef A, Ben-Arie G, Pinsk I (2019) Protection of colorectal anastomosis with an intraluminal bypass device for patients undergoing an elective anterior resection: a pilot study. Tech Coloproctol

26. Law WL, Choi HK, Lee YM, Ho JW, Seto CL (2007) Anastomotic leakage is associated with poor long-term outcome in patients after curative colorectal resection for malignancy. J Gastrointest Surg 11:8-15 
3

4 DISCLOSURES

5 Prof. J.H. Lefevre is a consultant for SafeHeal.

6 Prof. J.H. Lefevre has received funding from SafeHeal to support congress registration and 7 travel fees.

8 Dr. A. D’Urso and Dr. N. Komen have no conflicts of interest to disclose.

9

10

11 FIGURES LEGENDS

12 Figure 1a. Colovac Device

13 Figure 1b. Colovac Device anchored in the colon with the high vacuum drainage system

14 Figure 2. Patients Overview

15 
Table 1. Patients' characteristics and surgical procedures

\begin{tabular}{|c|c|}
\hline & $\mathrm{n}(\%)$ \\
\hline Number of patients & $15(100)$ \\
\hline Male Gender & $10(67)$ \\
\hline Median Age (years (IQR)) & $60(46-70)$ \\
\hline Median BMI $\left(\mathrm{kg} / \mathrm{m}^{2}(\mathrm{IQR})\right)$ & $24(22-28)$ \\
\hline Active smoking & $0(0)$ \\
\hline Diabetes & $3(20)$ \\
\hline Arterial Hypertension & $3(20)$ \\
\hline $\begin{array}{l}\text { Clinical cancer staging } \\
\text { T1 } \\
\text { T2 } \\
\text { T3 } \\
\text { T4 }\end{array}$ & $\begin{array}{c}4(27) \\
2(13) \\
8(53) \\
1(7)\end{array}$ \\
\hline $\begin{array}{l}\text { Tumor Size } \\
\qquad 2.5 \mathrm{~cm} \\
\quad>2.5 \mathrm{~cm}\end{array}$ & $\begin{array}{c}6(40) \\
9(60) \\
5.14(0-6)\end{array}$ \\
\hline Median time from diagnosis to surgery (months (IQR)) & $3.7(1.5-4.6)$ \\
\hline $\begin{array}{l}\text { Neoadjuvant treatment } \\
\text { Chemotherapy only } \\
\text { Radiotherapy only } \\
\text { Radio chemotherapy } \\
\text { No neoadjuvant treatment }\end{array}$ & $\begin{array}{c}1(7) \\
1(7) \\
8(53) \\
5(33)\end{array}$ \\
\hline $\begin{array}{l}\text { Surgical approach } \\
\text { Laparoscopy }\end{array}$ & $15(100)$ \\
\hline $\begin{array}{l}\text { Median duration of surgery }(\mathrm{min}(\mathrm{IQR})) \\
\text { Type of anastomosis }\end{array}$ & $260(218-360)$ \\
\hline Coloanal Handsewn & $4(26.7)$ \\
\hline Colorectal Stapled & $11(73.3)$ \\
\hline End to end & $5(33.3)$ \\
\hline $\begin{array}{l}\text { Side to end } \\
\text { J pouch }\end{array}$ & $\begin{array}{l}9(60) \\
1(6.7)\end{array}$ \\
\hline Median anastomosis height from anal margin (cm (IQR)) & $2(1-4)$ \\
\hline Use of pelvic drain & $13(87)$ \\
\hline $\begin{array}{l}\text { Concomitant surgery } \\
\text { Right Hepatectomy } \\
\text { Hepatic wedge resection } \\
\end{array}$ & $\begin{array}{l}1(7) \\
1(7)\end{array}$ \\
\hline
\end{tabular}


Table 2. Colovac placement and removal.

\begin{tabular}{|c|c|}
\hline Items & $\mathbf{N}(\%)$ \\
\hline \multicolumn{2}{|l|}{ Colovac placement } \\
\hline Median duration & $7(3-10)$ \\
\hline \multicolumn{2}{|l|}{ Technical ease of introducer introduction* } \\
\hline Very easy & $5(33)$ \\
\hline Easy & $9(60)$ \\
\hline Moderate & $1(7)$ \\
\hline Difficult & $0(0)$ \\
\hline Impossible & $0(0)$ \\
\hline \multicolumn{2}{|l|}{ Technical ease of introducer removal* } \\
\hline Very easy & $6(40)$ \\
\hline Easy & $6(40)$ \\
\hline Moderate & $3(20)$ \\
\hline Difficult & $0(0)$ \\
\hline Impossible & $0(0)$ \\
\hline \multicolumn{2}{|l|}{ Implantation site reached } \\
\hline Yes & $14(93)$ \\
\hline No & $0(0)$ \\
\hline $\begin{array}{l}\text { Accidental Colovac pullout during introducer } \\
\text { removal - Replaced by another device }\end{array}$ & $1(7)$ \\
\hline \multicolumn{2}{|l|}{ Colovac anchoring } \\
\hline 14 days of implantation & $12(80)$ \\
\hline Device migration & $3(20)$ \\
\hline \multicolumn{2}{|l|}{ Colovac retrieval } \\
\hline Median duration & $10(5-20)$ \\
\hline \multicolumn{2}{|l|}{ Technical ease of Colovac retrieval } \\
\hline Very easy & $6(33)$ \\
\hline Easy & $7(54)$ \\
\hline Moderate & $0(0)$ \\
\hline Difficult & $2(13)$ \\
\hline Impossible & $0(0)$ \\
\hline Absence of feces below the anchoring site & $15(100)$ \\
\hline \multicolumn{2}{|l|}{ Mucosal appearance ${ }^{* *}$} \\
\hline \multicolumn{2}{|l|}{ At the anchoring site } \\
\hline Normal & $2(13)$ \\
\hline Inflammatory & $6(40)$ \\
\hline Bleeding & $4(27)$ \\
\hline Ulcer & $2(13)$ \\
\hline Perforation & $0(0)$ \\
\hline \multicolumn{2}{|l|}{ Above the anchoring site } \\
\hline Normal & $11(73)$ \\
\hline Inflammatory & $1(7)$ \\
\hline Bleeding & $2(13)$ \\
\hline Ulcer & $0(0)$ \\
\hline Perforation & $0(0)$ \\
\hline \multicolumn{2}{|l|}{ At the anastomotic level } \\
\hline Normal & $12(80)$ \\
\hline Inflammatory & $0(0)$ \\
\hline Bleeding & $2(13)$ \\
\hline Ulcer & $0(0)$ \\
\hline Perforation & $0(0)$ \\
\hline
\end{tabular}

Times are given in min (IQR) 
*Technical ease of introducer introduction and removal have been evaluated by investigators using a Lickert scale ranked from 1 (very easy) to 5 (impossible) depending on the deployment force.

**Missing data for one patient as Colovac was removed manually in the OR without access to endoscopic evaluation 


\begin{tabular}{|c|c|c|c|}
\hline Item & $\begin{array}{c}1 \text { week } \\
\mathrm{N}(\%)\end{array}$ & $\begin{array}{c}2 \text { weeks } \\
\mathrm{N}(\%)\end{array}$ & $\begin{array}{c}3 \text { months } \\
\mathrm{N}(\%)\end{array}$ \\
\hline Overall morbidity & $3(20)$ & $2(13.3)$ & $5(33.3)$ \\
\hline Medical complication & & & \\
\hline Ascites & & $1(7)$ & \\
\hline Seizure & & & $1(7)$ \\
\hline Surgical complication & & & \\
\hline Incomplete anastomotic healing & & $2(13.3)$ & \\
\hline Device migration with leakage & $3(20)$ & & \\
\hline Pelvic collection & & & $3(20)$ \\
\hline Bowel obstruction & & & $1(7)$ \\
\hline Peritonitis & $1(7)$ & & \\
\hline
\end{tabular}

Patient tolerance to the presence of vacuum system

$\begin{array}{lcc}1 \text { (Full acceptance) } & 10(66.7) & 8(53.3) \\ 2 & 5(33.3) & 4(26.7) \\ 3 & 0(0) & 1(7) \\ 4 & 0(0) & 0(0) \\ 5 \text { (No acceptance) } & 0(0) & 0(0) \\ \text { Missing data* }^{*} & 0(0) & 2(13.3)\end{array}$

Patients tolerance to the presence of sheath protruding out of the anus

1 (Full acceptance)

2

3

4

5 (No acceptance)

Missing data*

$9(60) \quad 6(40)$

$5(33.3) \quad 4(26.7)$

$1(6.7) \quad 2(13.3)$

$0(0) \quad 1(6.7)$

$0(0) \quad 0(0)$

$0(0) \quad 1(13.3)$

NIH's PROMIS health score (median IQR) $\quad 44$ (38-51) $36(15-46) \quad 15(8-20)$

Stoma reversal $1(20)$

Some patients experienced more than one complication. *Questionnaires have not been fully filled by all patients.

Table 3. Patient acceptance and post operative morbidity 
15 Patients enrolled

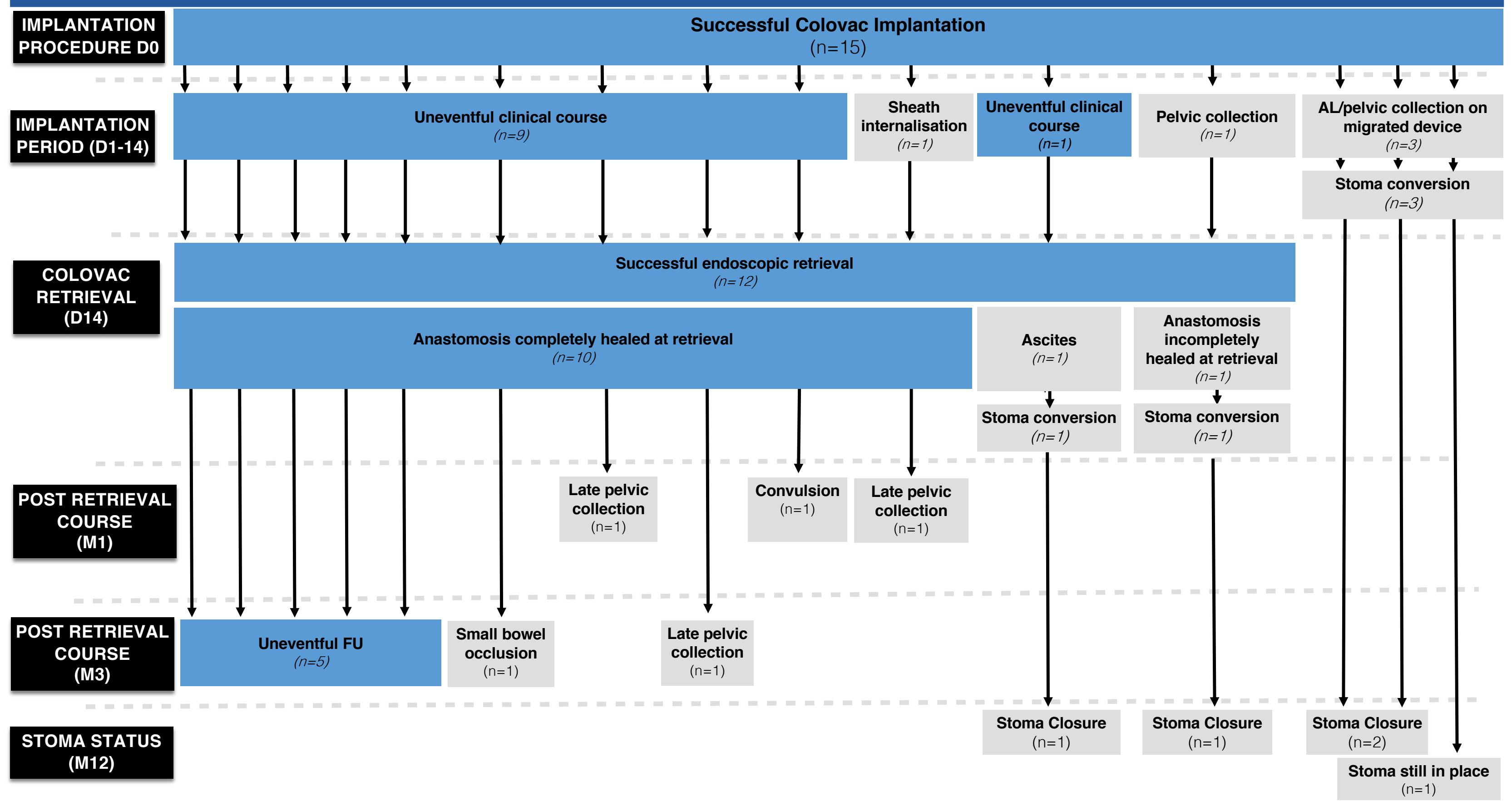

